\title{
Novel human sex-typing strategies based on the autism candidate gene NLGN4X and its male-specific gametologue NLGN4Y
}

\author{
Stephan Maxeiner ${ }^{1 *}$ D, Martina Sester ${ }^{2}$ and Gabriela Krasteva-Christ ${ }^{1}$
}

\begin{abstract}
Background: Since the early days of PCR techniques, sex identification, "sex-typing," of genomic DNA samples has been a fundamental part of human forensic analysis but also in animal genetics aiming at strategic livestock breeding. Most analyses are employing the AMELX/AMELY gene loci on the $X$ and $Y$ chromosomes present in most mammals. We hypothesize that sex-typing in humans is also possible based on the genes NLGN4X and NLGN4Y, which represent $X$ and $Y$ chromosome-specific copies of a common ancestral neuroligin-4 orthologue.

Methods: Genomic DNA was isolated from human blood and buccal cell samples (total $n=111$ ) and submitted to two different strategies: (a) a traditional two-primer PCR approach detecting an insertion/deletion (indel) polymorphism immediately upstream of the translational start on exon 1 and (b) detection of a single nucleotide polymorphism, SNP, on the translational stop carrying exon 7. The SNP detection was based on a quantitative PCR approach (rhAMP genotyping) employing DNA/RNA hybrid oligonucleotides that were blocked and which could only be activated upon perfect annealing to the target DNA sequence.

Results: All indel PCR-tested human DNA samples showed two bands for males representing $X$ - and Y-specific copies of NLGN4 and a single band for female samples, i.e., homozygosity of NLGN4X and absence of NLGN4Y, in accordance with the self-reported sex of the donors. These results were in perfect agreement with the results of the rhAMP-based SNP-detection method: all males were consequently positive for both alleles, representing either SNP variant, and females were interpreted as homozygous regarding the SNP variant found in NLGN4X. Both methods have shown reliable and consistent results that enabled us to infer the sex of donor DNA samples across different ethnicities.

Conclusions: These results indicate that the detection of human NLGN4XY is a suitable alternative to previously reported methods employing gene loci such as AMELXY. Furthermore, this is the first report applying successfully the rhAMP-genotyping strategy as a means for SNP-based sex-typing, which consequently will be applicable to other gene loci or different species as well.
\end{abstract}

Keywords: Neuroligin-4, Amelogenin, Chromosomes, sex-typing, rhAMP genotyping

\footnotetext{
*Correspondence: stephan.maxeiner@uni-saarland.de

'Institute of Anatomy and Cell Biology, Saarland University, Homburg,

Germany

Full list of author information is available at the end of the article
}

(c) The Author(s). 2019 Open Access This article is distributed under the terms of the Creative Commons Attribution 4.0 International License (http://creativecommons.org/licenses/by/4.0/), which permits unrestricted use, distribution, and reproduction in any medium, provided you give appropriate credit to the original author(s) and the source, provide a link to the Creative Commons license, and indicate if changes were made. The Creative Commons Public Domain Dedication waiver (http://creativecommons.org/publicdomain/zero/1.0/) applies to the data made available in this article, unless otherwise stated. 


\section{Background}

A fundamental question in forensic sciences regarding the origin and identity of an unknown human DNA sample is whether it derives from a male or female donor. Since the identification of the $S R Y$ gene on the Y chromosome (sex-determining region on $\mathrm{Y}$ ) [1-3], an essential distinguishing mark has been at hand as any other gene specific to the $\mathrm{X}$ chromosome is present in both, females and males. About 25 years ago, when testing for the presence of the $S R Y$ gene by PCR was technically novel to most research laboratories, the absence of a PCR product in any given reaction did not unequivocally indicate female origin since an internal control of the DNA quality and PCR performance was missing. This problem was eventually eliminated after two similar but not identical copies of the vertebrate amelogenin gene have been identified in mammals, which were named $A M E L X$ and $A M E L Y$, accordingly [4]. AMELX/Y are "gametologues" that have evolved early in mammalian (eutherian) evolution [5] and are localized on the $\mathrm{X}$ and $\mathrm{Y}$ chromosomes, respectively, just outside the pseudoautosomal region [6]. Sequence alignment of both genes revealed striking similarities but also single nucleotide polymorphisms as well as insertions or deletions ("indels"). Different combinations of primers have been designed hybridizing to highly similar or even identical regions. The resulting PCR product/s allow identifying indel variations by one reaction and, consequently, inferring the sex of the DNA sample: detection of $A M E L X$ serves as an internal control and the additional presence of $A M E L Y$ concludes DNA origin of a male [7-9]. The AMELX/Y diversity as means of sex determination has been demonstrated in other mammalian species, such as dogs [10], horses [11], pigs [12], sheep [13], and many others. The identification of $A M E L X$ and $A M E L Y$ genes has been widely accepted as means of testing for the presence of both sex chromosomes and is well established in forensic genetics and livestock breeding. In the light of the human genome project, potential alternative gene loci have been identified, such as the gene encoding for the zinc finger protein on $\mathrm{X}$ and $\mathrm{Y}$ $(Z F X / Z F Y)[14,15]$, or predicted based on nextgeneration sequencing data [16].

Comparable to amelogenin, neuroligin-4 also retains two separate copies on both human sex chromosomes, i.e., NLGN4X and NLGN4Y (cf. NCBI database). Therefore, this gene pair potentially qualifies for sex-typing as well. Neuroligin- 4 belongs to the neuroligin family of neural cell adhesion molecules, which are located at the postsynaptic side in neurons and interact transsynaptically with neurexin proteins [17]. Mutations in several neuroligin genes have been identified to result in neurological disorders [17]. Most prominently mutations in the NLGN3 and NLGN4X genes have been found to be underlying causes of autism spectrum disorders, ASD [18].

Considering human $N L G N 4 X / Y$ as a suitable gene pair to identify the sex of unspecified donor DNA, we aimed at developing a simple protocol to detect a length polymorphism immediately upstream of the start codon applying standard PCR strategies available in many research labs. Many short nucleotide polymorphisms between both genes led us to consider rhAMP genotyping (IDT, Coralville, USA) as an alternative tool to distinguish both genes. This PCR-based strategy uses two "blocked" oligonucleotides, which incorporate a single ribonucleotide in a given deoxy-ribonucleotide sequence matching the single base discrepancies between different alleles [19]. RNaseH2-mediated cleavage of the correct RNA/DNA hybrid restores a functional 3-prime hydroxyl group upstream of this hybrid consequently allowing proper elongation by DNA polymerases. This method has been shown to be equally suitable or superior to other allelic discrimination technologies [20] and can also be used to detect alternatively spliced small exons [21].

Our study demonstrates that $N L G N 4 X / Y$ gene detection is suitable for human sex determination across different ethnicities using two alternative experimental strategies. Besides conventional PCR-based strategies, this is the first report in which rhAMP genotyping has been applied to infer the sex of human DNA samples.

\section{Methods}

\section{Bioinformatical analysis}

The following genomic sequence information was retrieved from the NCBI database (www.ncbi.nlm.gov/ gene), NLGN4X: Homo sapiens (Gene ID: 57502), Gorilla gorilla (101131855), Pan troglodytes (465474), Pan paniscus (100994646), Pongo abelii (100173414), and NLGN4Y: Homo sapiens (22829), Gorilla gorilla (Accession number: FJ532261.1), Pan troglodytes (Accession number: XM_009445767.3). For overview of annotated human $N L G N 4 X / Y$ sequences, see Additional file 1. Sequences were aligned using MultAlin (http://multa lin.toulouse.inra.fr/multalin) with default alignment settings for DNA analysis ("DNA-5-0").

\section{DNA extraction}

DNA was isolated from 105 retention blood samples from clinical routine diagnostics at the Department of Transplant and Infection Immunology, Saarland University, Germany, prior to discarding. To establish and optimize initial PCR conditions, we extracted DNA after the collection of buccal cells from six volunteering donors upon obtaining written informed consent and total anonymization of samples. Overview of sample ethnicity and sex distribution is summarized in Table 1. DNA 
Table 1 Sex and ethnicity distribution. A total of $N=111$ DNA samples were tested from male and female donors. Thirteen samples were from ethnicities other than Caucasian

\begin{tabular}{ll}
\hline Sex & $N($ total $)=111$ \\
Female & 37 \\
Male & 74 \\
Ethnicity & $N($ total $)=111$ \\
Afro-American & 3 \\
Asian & 3 \\
Caucasian & 98 \\
Indian & 1 \\
Middle Eastern & 2 \\
Sub-Saharan & 4 \\
\hline
\end{tabular}

sample preparation has been performed by two different methods based on the tissue sample, (a) buccal mucosa cells or (b) blood. Buccal mucosa cell samples were harvested from donors by collecting $40 \mathrm{ml}$ of mineral water, which had been used in a thorough mouth rinse for 1 min. Cells and debris were collected at $4000 \times g$, the supernatant was discarded, and the sediment was resuspended in $5 \mathrm{ml}$ lysis buffer $(0.1 \mathrm{M}$ Tris, $5 \mathrm{mM}$ EDTA, $0.2 \mathrm{M} \mathrm{NaCl}, 0.2 \%$ SDS, at $\mathrm{pH} 8.5$ ), supplemented with $50 \mu \mathrm{l}$ proteinase K-solution $(20 \mathrm{mg} / \mathrm{ml}$, Bioline, Luckenwalde, Germany), and incubated at $55{ }^{\circ} \mathrm{C}$ overnight. DNA extraction from buccal cell lysate was performed according to standard procedures using the phenol/ chloroform extraction method. Genomic DNA from heparin/EDTA-blood samples was isolated using the Quick-DNA Miniprep Plus Kit (Zymo Research Europe $\mathrm{GmbH}$, Freiburg, Germany). DNA concentration was quantified using a ND-1000 spectrophotometer (NanoDrop, Thermo Scientific, Waltham, MA, USA) and diluted to $5 \mathrm{ng} / \mathrm{ml}$ using IDTE-buffer (IDT, Coralville, Iowa, USA). All other chemical reagents have been purchased from Sigma-Aldrich (Darmstadt, Germany).

\section{PCR analysis}

The following primer combination has been used to identify an indel region (194 bp) immediately upstream of the respective start codons of the NLGN4X and NLGN4Y genes: MX17673 (sense) 5'-GAAGAGCCAG CCAGTGTTCTAGGTG-3' and MX17674 (antisense) 5'-ACATGGTTCAAATCTGCATCCACATCC-3'. PCR reaction was performed according to the manufacturer's recommendation using Q5 High-Fidelity 2x Master Mix (New England Biolabs GmbH, Frankfurt, Germany), 0.5 $\mu \mathrm{M}$ of each primer (MX17673/MX17674, IDT), and a total sample amount of $10 \mathrm{ng}$ per run (reaction volume $25 \mu \mathrm{l})$. PCR reactions were loaded on a T100 Thermal Cycler (Bio-Rad Laboratories, Munich, Germany) using the following parameters: initial denaturation at $98{ }^{\circ} \mathrm{C}$ for $30 \mathrm{~s}, 35 \times$ cycle $\left(98{ }^{\circ} \mathrm{C}\right.$ for $10 \mathrm{~s}, 65^{\circ} \mathrm{C}$ for $20 \mathrm{~s}, 72{ }^{\circ} \mathrm{C}$ for $30 \mathrm{~s}$ ), and final extension at $72{ }^{\circ} \mathrm{C}$ for $1 \mathrm{~min}$. Finally, PCR products were separated on a $2 \%$ agarose gel supplemented with MIDORI Green (1:10,000; Nippon Genetics Europe GmbH, Dueren, Germany) and documented using a Gel Doc System (Bio-Rad Laboratories).

\section{SNP genotyping}

SNP genotyping has been performed using the rhAMPgenotyping strategy by IDT. Briefly, three potential base differences have been identified between both coding regions within the NLGN4X and NLGN4Y genes that appeared suitable to apply this strategy (Table 2). Potential primer combinations have been identified using the rhAMP-genotyping design tool (IDT). Fluorescent dyeconjugation (FAM or VIC) to and blocking specification of the respective oligonucleotides as well as further modifications to the alternative primers remained under the discretion of IDT. Each run consisted of $10 \mathrm{ng}$ sample DNA $(2 \mu \mathrm{l}), 5.3 \mu \mathrm{l}$ PCR mix (combined master and reporter mix), $0.5 \mu \mathrm{l}$ rhAMP-SNP assay (20×), and $2.2 \mu \mathrm{l}$ nuclease-free water. All qPCR reactions were run on a CFX Connect System (Bio-Rad Laboratories) with adjusted thermal cycling conditions: enzyme activation at $95{ }^{\circ} \mathrm{C}$ for $10 \mathrm{~min}$ and $40 \times$ cycle $\left(95^{\circ} \mathrm{C}\right.$ for $10 \mathrm{~s}, 60{ }^{\circ} \mathrm{C}$ for $30 \mathrm{~s}, 68{ }^{\circ} \mathrm{C}$ for $20 \mathrm{~s}$ ). The results of the individual runs were displayed as puncta on an XY scatter blot based on relative fluorescent units (RFU values) suited for allelic discrimination (CFX Connect System software, Bio-Rad Laboratories).

\section{Results}

Identification of indels and SNPs in the NLGN4X/Y genes To validate our hypothesis that the gene pair NLGN4X and NLGN4Y could be employed to distinguish male and female DNA samples, we iteratively compared the available genomic sequence information for both genes encompassing all protein coding exons. The general numbering of exons regarding all four neuroligin genes is based on a previous publication by Bolliger [22], which in case for neuroligin-4 results in the formal absence of exon 2 (Fig. 1a). Both genes are covering approx. $200 \mathrm{~kb}$ displaying their highest similarity in the vicinity of and within their exons. In order to develop a simple PCR strategy to discriminate both genes, two fundamental prerequisites needed to be met, firstly, the oligonucleotides should not contain ambiguous bases to accommodate identical annealing conditions for either gene, and secondly, both amplicons must be readily distinguishable after a short separation time using agarose gel electrophoresis. The validation of a SNP-based strategy by rhAMP genotyping meets different criteria (see the manufacturer's recommendation). To distinguish both human NLGN4 genes ("alleles"), we chose stretches in 
Table 2 rhAMP-SNP-assay sequences. Each rhAMP-assay consists of a set of allele-specific primers to distinguish between both alleles as well as a locus-specific primer common to both allelic variants. 5-prime modifications to each allele-specific primer regarding FAMNIC-based fluorescence detection and 3-prime "blocking" immediately downstream of the given ribonucleotide remain subject to the vendor's discretion (IDT)

\begin{tabular}{llll}
\hline Assay name & Allele-specific primer 1 & Allele-specific primer 2 & Locus-specific primer \\
\hline SNP_A & CCCCGAGCCAAAGATG & CCCCCGAGCCAAAGATA & GCGGATTGAGGAGAATGTGGGA \\
SNP_B & ATTCAGAGCGGCACC & CATTCAGAGCGGCACT & GCGACCTTGTCTGCCAATATCC \\
SNP_C & AGAGAAACACCACAAATGATATCG & CAGAGAAACACCACAAATGATATCA & GCATCGTGTTCCAGCTGCTT \\
\hline
\end{tabular}

which both genes were identical except for a single base difference. Three potential loci have been identified in exon 5,6 , and 7 , respectively, complying with this prerequisite (SNP_A, B, and C in Fig. 1b, c). Whereas SNP_ $\mathrm{A}$ and $\mathrm{B}$ represent loci with synonymous base changes, the base difference between NLGN4X and NLGN4Y in SNP_C results in a change from alanine (NLGN4X) to threonine (NLGN4Y) (Fig. 1c).

\section{PCR detection of an indel variation upstream of the start codon}

In an initial screening of several potentially suitable indel regions using different sets of oligonucleotides, we found one pair that robustly distinguished a region immediately upstream of the start codon (Fig. 1d). Human genomic DNA isolated from buccal cells as well as from human blood samples were submitted to PCR reaction. In the case for NLGN4X, a longer amplicon (381 bp) was expected than for NLGN4Y (187 bp) (Fig. 2). Theory has it that the presence of both bands represent male donor DNA, and a single band reflects female donor DNA serving as a control for PCR performance. Without any exception, all tested samples $(N=111)$ showed PCR results that were matching the self-reported sex of their donors across different ethnicities (74 males and 37 females, Table 1; Additional file 2). A comparison to sequence information available from other hominid genomes suggests that this PCR-based strategy should also apply to chimpanzee DNA (Pan troglodytes, Table 3).

\section{rhAMP genotyping of NLGN4X/Y SNPs}

Since NLGN4X and NLGN4Y retain high homology in their coding sequence $(96.9 \%)$, we regarded single nucleotide polymorphisms as "pseudo-allelic variations" and, therefore, considered the rhAMP-genotyping system as potentially suitable means to verify the presence of either gene in order to infer the sex of the donor. As a proof of principle, we tested three different assays (one for each SNP) using five male and female samples that had been validated by PCR (Fig. 3a). Only the assay detecting the non-synonymous base change (SNP_C, see Fig. 1c and Table 2) resulted in a proper allelic separation of both genes reminiscent of previous publications [20]. Assays A and B detected solely NLGN4X but failed to detect NLGN4Y. Subsequently, we submitted our set of donor DNA to rhAMP genotyping using assay SNP_C and found that all samples $(N=111)$ separated in two non-overlapping clusters suggesting the "allelic" combinations NLGN4X/NLGN4X (female) and NLGN4X/ NLGN4Y (male) (Fig. 3b; Additional files 3 and 4). The results were identical to our previous results using conventional PCR to detect an indel polymorphism upstream of the start codon. In silico analysis revealed that this particular rhAMP-based allelic discrimination should also be applicable to sex-type western gorillas but not chimpanzees (Table 3).

\section{Discussion}

Sex identification based on DNA screening receives broad interest not only regarding forensic sciences but also in animal breeding, e.g., in horse breeding [23]. Sole detection of the male-specific SRY gene by PCR, however, is lacking an internal positive control to judge PCR performance or DNA quality. PCR protocols based on indel variations in the amelogenin genes are widely accepted, because $\mathrm{X}$ and $\mathrm{Y}$ chromosome-specific versions are present in many eutherian genomes. Since $A M E L X$ and $A M E L Y$ have deviated from a common ancestral gene [6], we hypothesized that due to shifts of the boundaries of the pseudoautosomal region [24], similar indel polymorphisms might be present in the human neuroligin-4 genes $(N L G N 4 X / Y)$, with their highly similar copies located on both human sex chromosomes. We aimed at developing a simple lab protocol based on PCR to identify an indel variation immediately upstream of the start codon. This yielded robust results, which in all cases tested were matching the sexes specified by their donors properly. Subsequently, three potential SNPbased assays using rhAMP-genotyping strategies were tested detecting differences in three coding exons (exons 5 , 6, and 7) roughly $200 \mathrm{~kb}$ downstream of the above verified indel variation. Only one assay, which was based on a non-synonymous base change between both genes on exon 7, showed the anticipated separation of two groups according to our hypothesis. In all samples, the rhAMP-genotyping strategy confirmed our results from PCR-based typing. Several reasons might explain the poor assay performance regarding SNP_A and B. These 


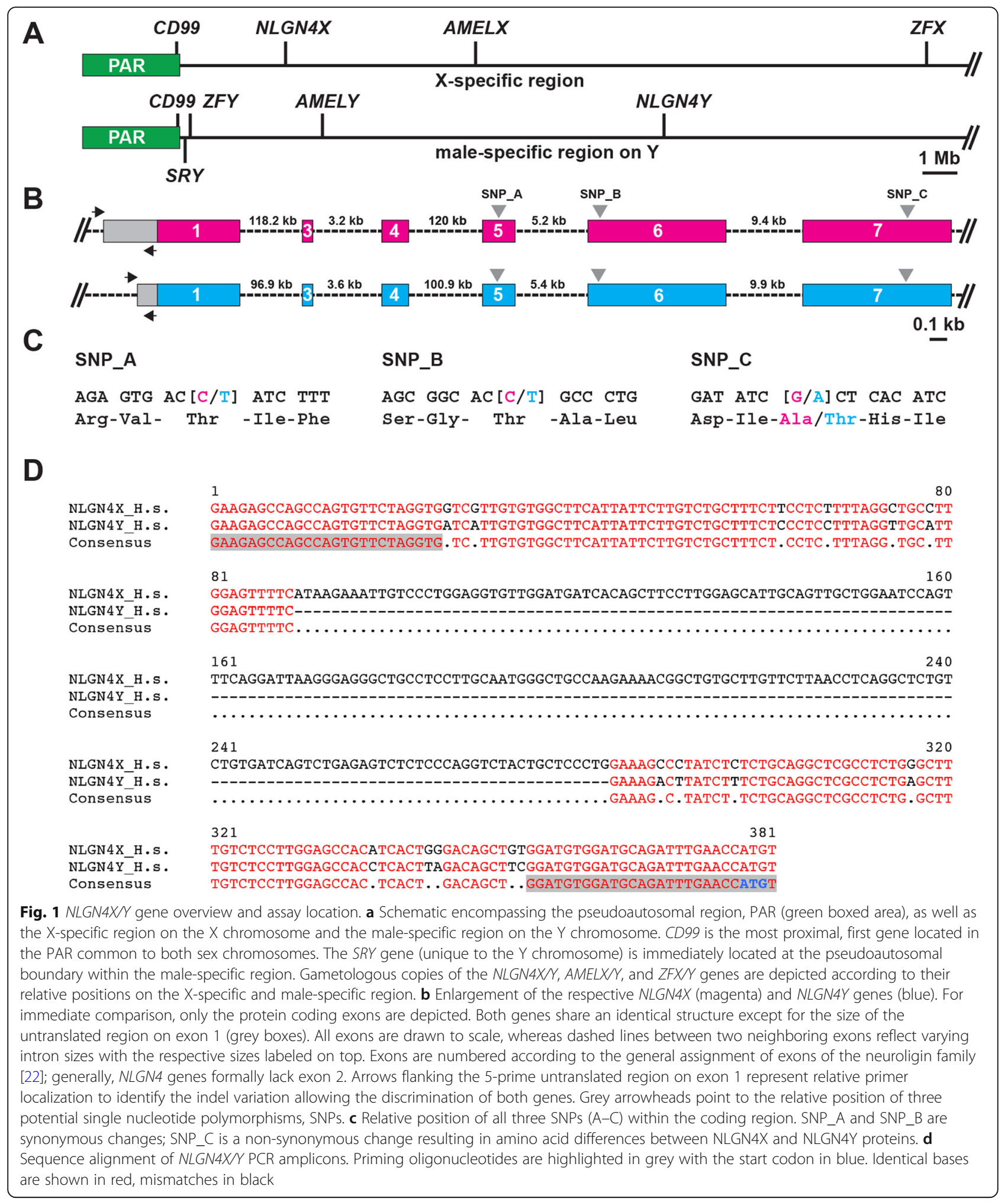

assays were based on synonymous base changes in the third position in both genes. Since both assays indicated the presence of $N L G N 4 X$, it might be possible that the bases in the respective $N L G N 4 Y$ gene do not correspond to the ones present in the current draft of the human genome sequence. The donor material on which the human genome project is based derives from a small number of donors with unspecified ethnicity [25]. It might be 


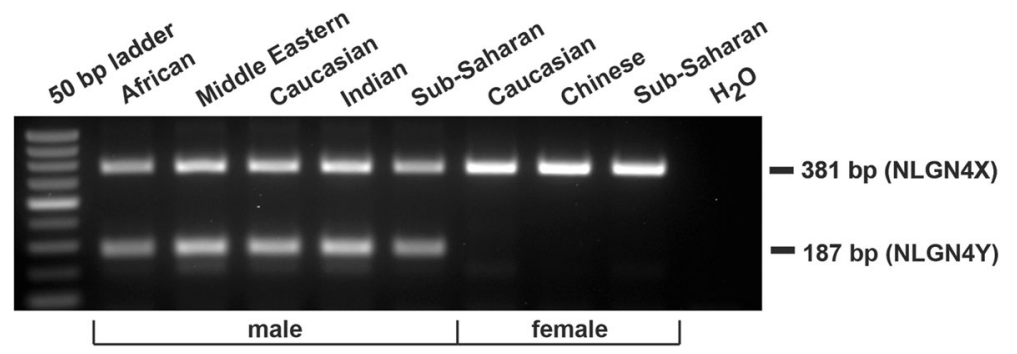

Fig. 2 PCR-based NLGN4XY sex-typing strategy. Representative picture showing PCR results separated on an agarose gel testing for an indel polymorphism between both NLGN4 gametologues. Male donor DNA of different ethnicities resulted consistently in two bands indicated by the presence of NLGN4X (381 bp) and NLGN4Y (187 bp). Female donor DNA resulted only in a single band (NLGN4X)

possible that these bases are found in particular ethnic groups, which are not covered by our analysis. This inability to clearly define the sex, however, further strengthens the results that we obtained assaying the non-synonymous base change in exon 7 (SNP_C assay). In our small but diverse group of ethnicities (Table 1), both genes had been detected consistently within the male cohort classifying this "allelic" polymorphism as a valid distinguishing marker between $N L G N 4 X$ and NLGN4Y.

Similar to current assays employing techniques to detect indel variations and polymorphisms in $A M E L X / Y$ [7-9], $Z F X / Y[14,15]$, or hypothesized human sex chromosome genes [16], $N L G N 4 X / Y$ is primarily suitable to discriminate both genes commonly found in $46, \mathrm{XX}$ or $46, \mathrm{XY}$ pairs. At this point, we cannot predict the performance of these assays in rare cases of aneuploidy found in Turner Syndrome (45,X), Klinefelter Syndrome $(47, \mathrm{XXY})$, double Y males $(47, \mathrm{XYY})$, or triple X females $(47, \mathrm{XXX})$ [26]. Furthermore, genomic rearrangements such as men with a translocated $S R Y$ gene, e.g., in cases of 46,XX sex reversal [27] or deletions including NLGN4X [28, 29], will affect the interpretation of the data regarding the PCR as well as the SNP-based strategy. Aneuploidy, mutations, deletions, and translocations, however, are considerably rare and are likely challenging any two-gene-based sex-typing strategy including tests regarding $A M E L X / Y$.
Although rhAMP-genotyping strategies have previously been applied for allelic discrimination [20] or quantitative assessment of alternative splicing [21], our study is the first in which this approach was implemented to infer the sex of donor DNA samples based on the presence or absence of sex chromosome-specific gene loci. This methodical approach should not be exclusive to the $N L G N 4 X / Y$ gene pair, but might also be applicable to distinguish $A M E L X / Y, Z F X / Y$, or any other suitable gene pair depending on the designing criteria.

It appears that the close relationship of humans to other hominids suggests that at least one sex-typing approach (PCR or rhAMP-based) might directly be applicable to other hominids without changing any of the parameters that we have established for human DNA samples. However, due to the absence of complementary genomic information for all NLGN4Y genes (e.g., gorilla, pygmy chimpanzee, and Sumatran orangutan), a conclusive statement regarding the application of both protocols seeks further validation.

During the course of our study on the validation of $N L G N 4 X / Y$ as a candidate gene pair for sex-typing applications, Jeong et al. have analyzed next-generation sequencing data from public databases and proposed several genes including $N L G N 4 X / Y$ [16]. The distinguishing features are based on short sequence segments found in transcripts and remain solely a bioinformatical strategy comparing NGS data sets. In contrast, both of

Table 3 Sex-typing strategies applicable to hominids. Overview of several primate species closely related to humans. Humans and chimpanzees share the same indel confirmed by available sequence information. The rhAMP strategy is applicable in humans and western gorillas for the given SNP

\begin{tabular}{|c|c|c|c|c|}
\hline \multirow[b]{2}{*}{ Species } & \multicolumn{2}{|c|}{ PCR genotyping (predicted amplicon size) } & \multicolumn{2}{|c|}{ rhAMP-genotyping (base at SNP_C position) } \\
\hline & NLGN4X & NLGN4Y & NLGN4X & NLGN4Y \\
\hline Homo sapiens & $381 \mathrm{bp}$ & $187 \mathrm{bp}$ & G & A \\
\hline Gorilla gorilla (western gorilla) & $381 \mathrm{bp}$ & $\mathrm{n} / \mathrm{a}$ & G & A \\
\hline Pan troglodytes (chimpanzee) & $381 \mathrm{bp}$ & $187 \mathrm{bp}$ & G & C \\
\hline Pan paniscus (pygmy chimpanzee) & $381 \mathrm{bp}$ & $\mathrm{n} / \mathrm{a}$ & G & $\mathrm{n} / \mathrm{a}$ \\
\hline Pongo abelii (Sumatran orangutan) & $377 \mathrm{bp}$ & $\mathrm{n} / \mathrm{a}$ & G & $\mathrm{n} / \mathrm{a}$ \\
\hline
\end{tabular}




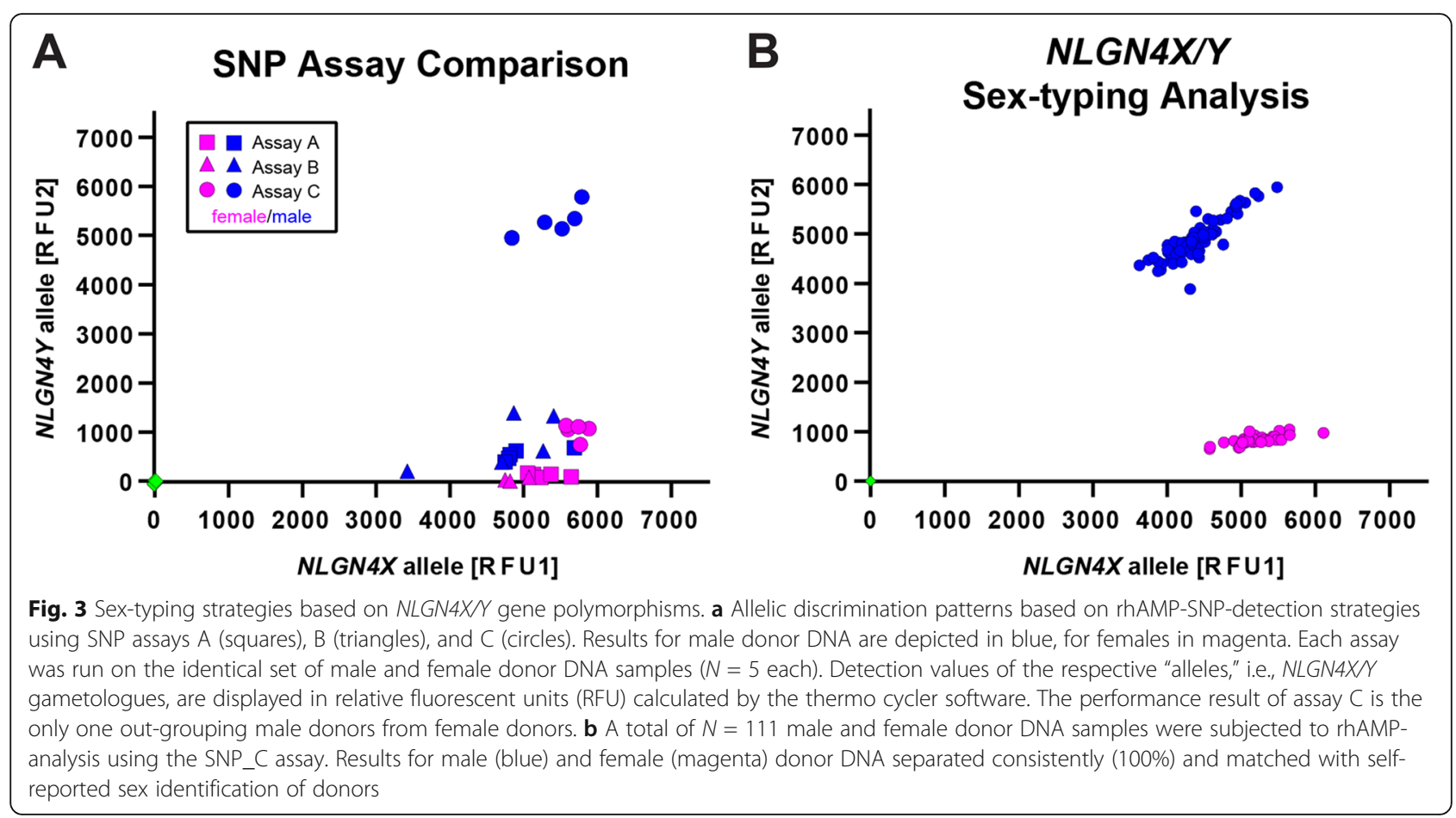

our protocols have been validated in over one hundred donor samples and are feasible in a research lab depending on sample numbers and equipment. The PCR-based indel detection is a considerable cheap approach for smaller sample numbers, whereas the rhAMP-based strategy allows high-throughput screening and could be combined with multiplexing PCR-technologies used in forensic sciences.

Primarily, we consider this study to be a proof of principle to successfully infer the sex based on the detection of NLGN4X and NLGN4Y genes. The use of this gene pair, however, is not per se superior to the detection of other gene pairs; we believe that it might be an alternative and/or complementation to previously reported gene loci. While human AMELY and ZFY are located more closely to the $S R Y$ gene and the pseudoautosomal boundary, NLGN4Y is located further away (approx. 14 Mb, Fig. 1a), and therefore, its detection basically confirms the presence of a different segment of the $\mathrm{Y}$ chromosome.

Based on the notion that NLGN4X and NLGN4Y are highly similar genes and located separately on the human sex chromosomes, we have established two protocols to detect both genes based on an indel variation upstream of the start codon or a single nucleotide difference in exon 7. Highly consistent results in sex determination in all human DNA samples originating from different ethnicities by both strategies are establishing $N L G N 4 X / Y$ sex-typing as a novel alternative to previously reported strategies and employed gene loci.

\section{Perspectives and significance}

In summary, our results introduce the human NLGN4X/ $Y$ gene pair as a basis for alternative strategies determining the presence of the $\mathrm{X}$ and $\mathrm{Y}$ chromosomes due to their shared evolutionary history. Testing for NLGN4X/ $Y$ is not just a mere addition to an exclusive club of selected genes, such as $A M E L X / Y$ or $Z F X / Y$; in just a single report, we suggest two different protocols encompassing both length and single nucleotide polymorphism for human sex determination. To our knowledge, this is the first report that uses rhAMP genotyping with blocked oligonucleotides to determine SNP polymorphisms allowing the inference of the sex from unspecified human donor material.

\section{Supplementary information}

Supplementary information accompanies this paper at https://doi.org/10. 1186/s13293-019-0279-x.

Additional file 1. Annotated human NLGN4X and NLGN4Y sequences Additional file 2. $P C R$ results of testing for the indel polymorphism

Additional file 3. Quantitative PCR-results on SNP_C

Additional file 4. Alignment for SNP_C

\section{Acknowledgements}

The authors would like to thank Candida Guckelmus for inventorying and providing human blood samples.

Authors' contributions

SM conceived and designed the study, performed the experiments, interpreted the data, and wrote the manuscript. MS and GKC provided 
reagents and edited the manuscript. All authors read and approved the final manuscript.

\section{Funding}

SM is a recipient of funding by HOMFOR (2017-2019). GKC receives funding from the DFG (SFB-TR152/P22).

\section{Availability of data and materials}

The dataset(s) supporting the conclusions of this article are included within the article and its additional files.

\section{Ethics approval and consent to participate}

No active blood sampling and patient contact was necessary for this study. All aliquots derived from an archive of blood samples (years 2005-2012) from the Department of Transplant and Infection Immunology inventorized under the approval of the local ethics committee. In order to establish PCR settings, volunteering donors of buccal cells approved the collection und use thereof by written informed consent. All samples were strictly anonymized following standards set by the Declaration of Helsinki on the use of human tissue samples.

\section{Consent for publication}

Not applicable

\section{Competing interests}

The authors declare that they have no competing interests.

\section{Author details}

${ }^{1}$ Institute of Anatomy and Cell Biology, Saarland University, Homburg, Germany. ${ }^{2}$ Department of Transplant and Infection Immunology, Saarland University, Homburg, Germany.

\section{Received: 21 October 2019 Accepted: 9 December 2019}

Published online: 18 December 2019

\section{References}

1. Gubbay J, Collignon J, Koopman P, Capel B, Economou A, Münsterberg A, et al. A gene mapping to the sex-determining region of the mouse $Y$ chromosome is a member of a novel family of embryonically expressed genes. Nature. 1990;346(6281):245-50.

2. Sinclair AH, Berta P, Palmer MS, Hawkins JR, Griffiths BL, Smith MJ, et al. A gene from the human sex-determining region encodes a protein with homology to a conserved DNA-binding motif. Nature. 1990;346(6281):240-4.

3. Stévant I, Papaioannou MD, Nef S. A brief history of sex determination. Mol Cell Endocrinol. 2018;468:3-10.

4. Nakahori Y, Takenaka O, Nakagome Y. A human X-Y homologous region encodes "amelogenin". Genomics. 1991;9(2):264-9.

5. Graves JA. Evolution of vertebrate sex chromosomes and dosage compensation. Nat Rev Genet. 2016;17(1):33-46.

6. Iwase M, Satta Y, Hirai Y, Hirai H, Imai H, Takahata N. The amelogenin loci span an ancient pseudoautosomal boundary in diverse mammalian species. Proc Natl Acad Sci U S A. 2003;100(9):5258-63.

7. Akane A, Shiono H, Matsubara K, Nakahori Y, Seki S, Nagafuchi S, Yamada M, Nakagome Y. Sex identification of forensic specimens by polymerase chain reaction (PCR): two alternative methods. Forensic Sci Int. 1991;49(1):81-8.

8. Sullivan KM, Mannucci A, Kimpton CP, Gill P. A rapid and quantitative DNA sex test: fluorescence-based PCR analysis of $X-Y$ homologous gene amelogenin. Biotechniques 1993:15(4):636-8, 640-1.

9. Mannucci A, Sullivan KM, Ivanov PL, Gill P. Forensic application of a rapid and quantitative DNA sex test by amplification of the $X-Y$ homologous gene amelogenin. Int J Legal Med. 1994;106(4):190-3.

10. Yan S, Bai C, Li Y, Li Y, Hou J, Zhao Z, et al. Sex identification of dog by PCR based on the differences in the AMELX and AMELY genes. Anim Genet. 2013;44(5):606.

11. Hasegaw T, Sato F, Ishida N, Fukushima Y, Mukoyama H. Sex determination by simultaneous amplification of equine SRY and amelogenin genes. J Vet Med Sci. 2000;62(10):1109-10.

12. Fontanesi L, Scotti E, Russo V. Differences of the porcine amelogenin $X$ and $Y$ chromosome genes (AMELX and AMELY) and their application for sex determination in pigs. Mol Reprod Dev. 2008;75(11):1662-8.
13. Pfeiffer I, Brenig B. X-and Y-chromosome specific variants of the amelogenin gene allow sex determination in sheep (Ovis aries) and European red deer (Cervus elaphus). BMC Genet. 2005;6:16.

14. Chong SS, Kristjansson K, Cota J, Handyside AH, Hughes MR. Preimplantation prevention of $\mathrm{X}$-linked disease: reliable and rapid sex determination of single human cells by restriction analysis of simultaneously amplified ZFX and ZFY sequences. Hum Mol Genet. 1993;2(8):1187-91.

15. Kim HL, Iwase M, Igawa T, Nishioka T, Kaneko S, Katsura Y, et al. Genomic structure and evolution of multigene families: "flowers" on the human genome. Int J Evol Biol. 2012;917678.

16. Jeong S, Kim J, Park W, Jeon H, Kim N. SEXCMD: Development and validation of sex marker sequences for whole-exome/genome and RNA sequencing. PLoS One. 2017;12(9):e0184087.

17. Südhof TC. Neuroligins and neurexins link synaptic function to cognitive disease. Nature. 2008:455(7215):903-11.

18. Jamain S, Quach H, Betancur C, Råstam M, Colineaux C, Gillberg IC, et al. Paris Autism Research International Sibpair Study. Mutations of the X-linked genes encoding neuroligins NLGN3 and NLGN4 are associated with autism. Nat Genet. 2003;34(1):27-9.

19. Dobosy JR, Rose SD, Beltz KR, Rupp SM, Powers KM, Behlke MA, et al. RNase $\mathrm{H}$-dependent PCR (rhPCR): improved specificity and single nucleotide polymorphism detection using blocked cleavable primers. BMC Biotechnol. 2011;11:80.

20. Broccanello C, Chiodi C, Funk A, McGrath JM, Panella L, Stevanato P. Comparison of three PCR-based assays for SNP genotyping in plants. Plant Methods. 2018:14:28.

21. Boucard AA, Maxeiner S, Südhof TC. Latrophilins function as heterophilic cell-adhesion molecules by binding to teneurins: regulation by alternative splicing. J Biol Chem. 2014;289(1):387-402.

22. Bolliger MF, Pei J, Maxeiner S, Boucard AA, Grishin NV, Südhof TC. Unusually rapid evolution of Neuroligin-4 in mice. Proc Natl Acad Sci U S A. 2008; 105(17):6421-6.

23. Aurich $\mathrm{C}$, Schneider J. Sex determination in horses - current status and future perspectives. Anim Reprod Sci. 2014;146(1-2):34-41.

24. Raudsepp T, Chowdhary BP. The Eutherian Pseudoautosomal Region Cytogenet Genome Res. 2015;147(2-3):81-94.

25. Lander ES, Linton LM, Birren B, Nusbaum C, Zody MC, Baldwin J, et al. International Human Genome Sequencing Consortium. Initial sequencing and analysis of the human genome. Nature. 2001;409(6822):860-921.

26. Skuse D, Printzlau F, Wolstencroft J. Sex chromosome aneuploidies. Handb Clin Neurol. 2018;147:355-76.

27. Zenteno-Ruiz JC, Kofman-Alfaro S, Méndez JP. 46,XX sex reversal. Arch Med Res 2001;32(6):559-566.

28. Mochel F, Missirian C, Reynaud R, Moncla A. Normal intelligence and social interactions in a male patient despite the deletion of NLGN4X and the VCX genes. Eur J Med Genet. 2008;51(1):68-73.

29. Lawson-Yuen A, Saldivar JS, Sommer S, Picker J. Familial deletion within NLGN4 associated with autism and Tourette syndrome. Eur J Hum Genet. 2008;16(5):614-8.

\section{Publisher's Note}

Springer Nature remains neutral with regard to jurisdictional claims in published maps and institutional affiliations.

Ready to submit your research? Choose BMC and benefit from

- fast, convenient online submission

- thorough peer review by experienced researchers in your field

- rapid publication on acceptance

- support for research data, including large and complex data types

- gold Open Access which fosters wider collaboration and increased citations

- maximum visibility for your research: over $100 \mathrm{M}$ website views per year

At $\mathrm{BMC}$, research is always in progress.

Learn more biomedcentral.com/submission 